\begin{tabular}{c}
\hline \hline Juntendo \\
Research Profiles \\
\hline \hline Juntendo Medical Journal \\
2016. $62(1), 56-57$
\end{tabular}

\title{
Department of Coloproctological Surgery
}

Our research focuses on colorectal cancer and inflammatory bowel disease (IBD), both of which have experienced rapid increases in incidence in recent years. With regard to the importance of postoperative QOL, we are persuading for the increased use of both minimally invasive surgery and early and non-invasive detection. We also aim to identify novel markers of colorectal tumor, which may allow improvement in diagnosis precision as well as tailor-made therapeutic protocols. Such an approach may also shed light on complex biological systems. We actively collaborate with both clinical and basic medical research departments to perform these investigations.

\section{Group leaders and research topics: \\ Kazuhiro SAKAMOTO (Professor)}

We are conducting basic and clinical studies on minimally invasive surgeries for colorectal cancer, including laparoscopic surgery and robotic surgery. Perioperative surgical stresses are to be evaluated to minimize the burden on the patient. Similar to surgical operation, we also assess the effectiveness of neoadjuvant chemotherapy and chemo-radiation therapy for locally advanced rectal cancer.

\section{Subgroup leader}

Michitoshi GOTO (Associate Professor)

Perioperative patient management for achieving early recovery.

\section{Yutaka KOJIMA (Associate Professor)}

Effectiveness and safety of robotic surgery for rectal cancer.

\section{Makoto TAKAHASHI (Associate Professor)}

Minimally invasive surgery for trans-anal approach procedures for rectal tumors.

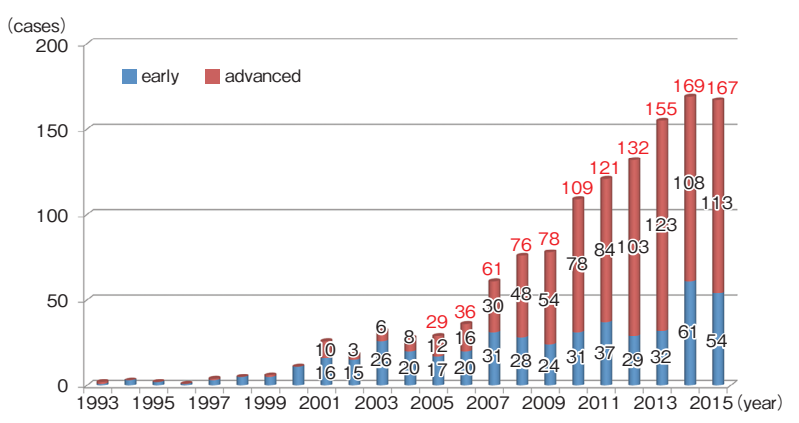

Number of laparoscopic colorectal cancer operation

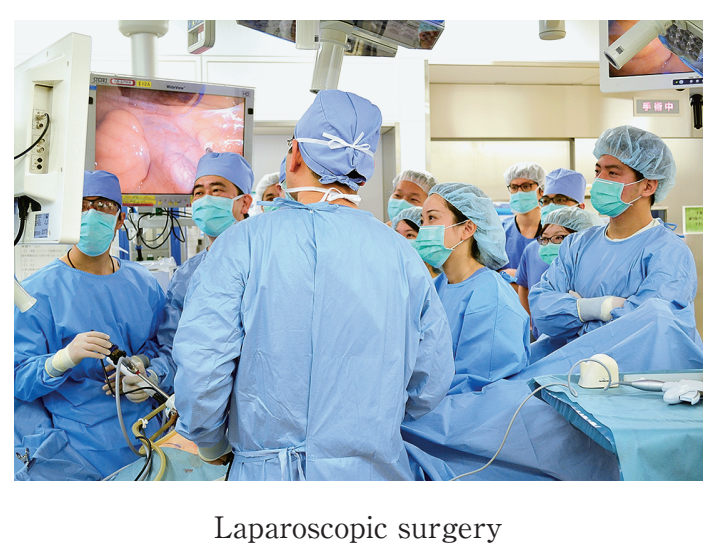

Yuichi TOMIKI (Senior Associate Professor)

Our group performs endoscopic treatment of colorectal tumor, and is investigating efficient and safe techniques for colorectal endoscopic submucosal dissection. One merit of this technique is the further reduction of treatment invasiveness for colorectal tumors, by reducing the use of additional surgical procedures.

\section{Hiromitsu KOMIYAMA (Lecturer)}

To identify novel markers of colorectal tumors, and to improve the precision of diagnosis, we conduct molecular studies on cells and biological molecules in patient blood and tissue samples. We perform comprehensive gene analyses with next-generation sequencing using colorectal cancer samples, and aim to identify various targets using these, as well as other, specific methods.

Circulating tumor cells (CTC) from real-time blood biopsy samples from patients are investigated to establish a database as well as to develop a proper analysis method. We also aim to identify micro-RNA or other molecules with cancer-specific activities. We utilize comparative genomic hybridization (CGH) to understand the biology of tumor cells and the mechanism of metastasis.

The etiology of IBD, a complex multifactorial disease, remains to be clarified. To elucidate the mechanism underlying IBD pathopoiesis, we are investigating the physiology and genetic basis of this disease. With an IBD model mouse with dextran sulphate sodium (DSS) -induced colitis, we are evaluating the effects of novel, specific agents for the treatment of IBD. 


\section{Publications}

1) Kawai M, Komiyama H, Hosoya M, Okubo H, Fujii T, Yokoyama N, Sato C, Ueyama T, Okuzawa A, Goto M, Kojima Y, Takahashi M, Sugimoto K, Ishiyama S, Munakata S, Ogura D, Niwa S, Tomiki Y, Ochiai T, Sakamoto K: Chromosome 17q deletion in the primary lesion of colorectal cancer has an impact on liver metastasis. Oncol Lett (in press).

2) Munakata S, Tashiro Y, Nishida C, Sato A, Komiyama H, Shimazu H, Dhahri D, Salama Y, Eiamboonsert S, Takeda K, Yagita H, Tsuda Y, Okada Y, Nakauchi H, Sakamoto K, Heissig B, Hattori K: Inhibition of plasmin protects against colitis in mice by suppressing matrix metalloproteinase 9-mediated cytokine release from myeloid cells. Gastroenterology, 2015; 148: 565-578.

3) Sugimoto K, Sakamoto K Tomiki Y, Kotake K, Sugihara K: Proposal of new classification for stage III colon cancer based on the lymph node ratio: analysis of 4,172 patients from multi-institutional database in Japan. Ann Surg Oncol, 2015; 22: 528-534.

4) Sakamoto K, Okazawa Y, Takahashi R, Sugimoto K, Komiyama H, Takahashi M, Kojima Y, Goto M, Okuzawa A, Tomiki Y: Laparoscopic intersphincteric resection using needlescopic instruments. J Minim Access Surg, 2014; 10: 1425-1428.

5) Tomiki Y, Ono S, Aoki J, Takahashi R, Ishiyama S, Sugimoto K, Yaginuma Y, Kojima Y, Goto M, Okuzawa
A, Sakamoto K: Treatment of internal hemorrhoids by endoscopic sclerothrapy with aluminum potassium sulfate and tannic acid. Diagn Ther Endosc, 2015; 2015: 517690.

6) Tomiki Y, Kawai M, Takehara K, Tashiro Y, Munakata S, Kure K, Ishiyama S, Sugimoto K, Kamiyama H, Takahashi M, Sakamoto K: Clinical pathway to discharge 3 days after colorectal endoscopic submucosal dissection. Dig Endosc, 2015; 27: 679-686.

7) Kawai M, Sakamoto K, Tomiki Y, Okuzawa A, Goto M, Kojima Y, Takahashi M, Komiyama H, Sugimoto K, Ishiyama S, Niwa K, Tashiro Y, Munakata S, Takehara K: Single-Incision laparoscopi colostomy or ileostomy for unresectable colorectal cancer. Juntendo Medical Journal, 2015; 61: 153-157

8) Takahashi N, Yamaguchi K, Ikenoue T, Fujii T, Furukawa Y: Identification of two Wnt-responsive elements in the intron of RING finger protein 43 (RNF43) gene. PLoS ONE, 2014; 9: e86582.

9) Fujii S, Yamamoto S, Ito M, Yamaguchi S, Sakamoto K, Kinugasa Y, Kokuba Y, Okuda J, Yoshimura K, Watanabe M: Short-term outcomes of laparoscopic intersphincteric resection from a phase II trial to evaluate laparoscopic surgery for stage 0/I rectal cancer: Japan Society of Laparoscopic Colorectal Surgery Lap RC. Surg Endosc, 2012; 26: 3067-3076. 